\title{
Effects of adolescent fluoxetine treatment on fear-, anxiety- or stress-related behaviors in C57BL/6J or BALB/CJ mice
}

\author{
Maxine Norcross, \\ Section on Behavioral Science and Genetics, Laboratory for Integrative Neuroscience, National \\ Institute on Alcohol Abuse and Alcoholism, National Institutes of Health, 5625 Fishers Lane, Room \\ 2N09, Rockville, MD 20852-9411, USA

\section{Mathur Poonam,} \\ Section on Behavioral Science and Genetics, Laboratory for Integrative Neuroscience, National \\ Institute on Alcohol Abuse and Alcoholism, National Institutes of Health, 5625 Fishers Lane, Room \\ 2N09, Rockville, MD 20852-9411, USA
}

\begin{abstract}
Abigail J. Enoch, Section on Behavioral Science and Genetics, Laboratory for Integrative Neuroscience, National Institute on Alcohol Abuse and Alcoholism, National Institutes of Health, 5625 Fishers Lane, Room 2N09, Rockville, MD 20852-9411, USA
\end{abstract}

\section{Rose-Marie Karlsson, Laboratory of Translational and Clinical Studies, Institute on Alcohol Abuse and Alcoholism, NIH, Bethesda, MD, USA}

Department of Clinical Neuroscience, Karolinska Institute, Stockholm, Sweden

\section{Jonathan L. Brigman,}

Section on Behavioral Science and Genetics, Laboratory for Integrative Neuroscience, National Institute on Alcohol Abuse and Alcoholism, National Institutes of Health, 5625 Fishers Lane, Room 2N09, Rockville, MD 20852-9411, USA

\section{Heather A. Cameron, \\ Unit on Neuroplasticity, Mood and Anxiety Disorders Program, National Institute of Mental Health, $\mathrm{NIH}$, Bethesda, MD, USA}

Judith Harvey-White, and Laboratory for Physiologic Studies, National Institute on Alcohol Abuse and Alcoholism, NIH, Rockville, MD, USA

\section{Andrew Holmes}

Section on Behavioral Science and Genetics, Laboratory for Integrative Neuroscience, National Institute on Alcohol Abuse and Alcoholism, National Institutes of Health, 5625 Fishers Lane, Room 2N09, Rockville, MD 20852-9411, USA, e-mail: holmesan@mail.nih.gov

\section{Abstract}

Rationale-5-Hydroxytryptamine (5-HT, serotonin) plays a major role in brain ontogeny. Disruption of 5-HT during early postnatal development produces lasting changes in rodent 'emotionrelated' behaviors. Adverse effects of treatment with serotonin reuptake inhibitor (SRI) 
antidepressants have been reported in human adolescents. However, the long-term effects of chronic SRI treatment during adolescence in rodents remain unclear.

Objectives-The objectives of the study are to assess the effects of fluoxetine treatment throughout the adolescent period in measures of fear-, anxiety- and stress-related endpoints in drug-free adults and to examine these effects in two genetic strains of mice differing in baseline stress-and anxietyrelated behaviors and sensitivity to SRIs.

Materials and methods- $\mathrm{C} 57 \mathrm{BL} / 6 \mathrm{~J}$ and $\mathrm{BALB} / \mathrm{cJ}$ mice received one of two fluoxetine doses for 4 weeks during adolescence (3-7 weeks old). A separate group of C57BL/6J and BALB/cJ mice received fluoxetine for 4 weeks during adulthood (8-12 weeks old). After a 3-week washout period, mice were tested for anxiety-like behaviors (novel open field, elevated plus-maze), fear conditioning and extinction, and stress-related responses to forced swim, as well as serotonin brain levels.

Results-Adolescent fluoxetine treatment did not increase adult measures of anxiety-, fear- or stress-related behaviors, or brain serotonin levels. The same duration of treatment in adulthood also had no effects on these measures when tested after a 3-week washout period.

Conclusions-In clear contrast with emotion-related abnormalities caused by preadolescent fluoxetine treatment or genetic inactivation of fluoxetine's pharmacological target, the 5-HT transporter, fluoxetine treatment throughout mouse adolescence did not produce detectable, lasting abnormalities in either "high" or "low anxiety" inbred mouse strains.

\section{Keywords}

Fluoxetine; SSRI; Antidepressant; Mouse; Anxiety; Fear; Depression; Stress; Development; Serotonin

\section{Introduction}

5-Hydroxytryptamine (5-HT, serotonin) plays a major role in neural development (Gaspar et al. 2003; Whitaker-Azmitia et al. 1996). There is growing evidence that disrupting 5-HT during development produces lasting changes in emotional behaviors and the neural systems subserving them. Genetic ablation of the 5-HT transporter (5-HTT) or postnatal inactivation of the 5-HT1A receptor causes increased anxiety- and depression-related behaviors in mice tested in adulthood (Alexandre et al. 2006; Ansorge et al. 2007; Gross and Hen 2004; Hariri and Holmes 2006). Similarly, some studies have shown that nonmutant mice and rats treated with the 5-HT reuptake inhibitor (SRI) fluoxetine or certain other antidepressants during the early postnatal period exhibit heightened anxiety- and depression-related behaviors when tested drug-free in adulthood (Andersen et al. 2002; Ansorge et al. 2008, 2004; Feng et al. 2001; Hansen et al. 1997; Hilakivi and Hilakivi 1987; Maciag et al. 2006a, 2006b; Prathiba et al. 1995; Velazquez-Moctezuma and Diaz Ruiz 1992; Yoo et al. 2000).

While these findings demonstrate detrimental effects of SRI treatment and 5-HTT inactivation during the early rodent postnatal period (corresponding to late gestation through early childhood in humans), it is not fully clear whether similar effects would be caused by SRI treatment at later developmental time points, notably adolescence. This issue is of important topical interest given recent concerns regarding potential adverse effects of SRI treatment in children and adolescents (Gibbons et al. 2007; Hammad et al. 2006; Usala et al. 2007; Whittington et al. 2004). One recent study showed that male rats treated with fluoxetine between 3 or 4 and 7 weeks of age did not show changes in anxiety-like behavior (LaRoche and Morgan 2007). Another study in mice found that treatment with fluoxetine from approximately 4 to 9 weeks of age prevented the increased depression-related phenotype in the forced swim test that was produced by postnatal maternal separation in the BALB/cJ strain, but per se was without significant effect on depression-related behavior and was not examined 
for possible effects on other endpoint measures such as anxiety-related assays (Bhansali et al. 2007).

In the present study, mice were treated with fluoxetine from 3 to 7 weeks of age; a period approximating to mid-childhood through adolescence in humans (Dohler and Wuttke 1975; Hefner and Holmes 2007b; Spear and Brake 1983). Lasting effects of adolescent fluoxetine treatment were then tested in adulthood after a drug-free washout period using a range of anxiety-, fear-, and stress-related endpoint measures. To test whether genetic strains with differing baseline trait levels of emotional reactivity and fluoxetine-sensitivity might respond differentially to adolescent fluoxetine treatment, we tested both the relatively "high-anxiety/ stress" BALB/cJ strain and the relatively "low-anxiety/stress' C57BL/6J strain (Anisman et al. 2001; Belzung and Griebel 2001; Dulawa et al. 2004; Millstein and Holmes 2007). For comparison of effects of adolescent versus adult treatment, a group of adult BALB/cJ and C57BL/6J mice was also fluoxetine-treated and tested.

\section{Materials and methods}

\section{Subjects}

Male BALB/cJ and C57BL/6J mice were obtained from The Jackson Laboratory (Bar Harbor, ME, USA) in the same shipment (aged 3 weeks for adolescence experiments, 8 weeks of age for the adult experiment). Mice were pair-housed (to avoid isolation stress) by strain and age in a temperature $\left(22 \pm 1^{\circ} \mathrm{C}\right)$ - and humidity $(45 \pm 15 \%)$-controlled vivarium under a 12-h light/ dark cycle (lights on 0600 hours) with ad libitum access to food. All experimental procedures were approved by the National Institute on Alcohol Abuse and Alcoholism Animal Care and Use Committee and followed the National Institute of Health guidelines outlined in the "Using Animals in Intramural Research."

\section{Fluoxetine treatment}

Fluoxetine hydrochloride (LKT Laboratories, St. Paul, MN, USA) was dissolved in tap water and made available ad libitum in the drinking water (refreshed weekly) in bottles covered with aluminum foil to protect the drug from light. Drug concentrations were determined based on body weight and known fluid consumption values in adult and adolescent mice in our laboratory and elsewhere (Dulawa et al. 2004; Hefner and Holmes 2007a). Adolescent mice received either a low $(80 \mathrm{mg} / \mathrm{l})$ or a high $(160 \mathrm{mg} / \mathrm{l})$ concentration of fluoxetine (tested in separate experiments). Adult mice received the lower concentration. The dose achieved was determined from weekly consumption. Ten mice of each strain and age received fluoxetine treatment, and ten received water, commencing on arrival and continuing for 4 weeks (i.e., 37 weeks of age for adolescents, 8-12 weeks of age for adults).

\section{Behavioral testing}

Behavioral testing began after a 3-week washout period (for schematic see Fig. 1a). There was at least 5 days between each test in the following order (putatively most stressful tests later in the sequence): (1) novel open field test for exploration and anxiety-related behavior, (2) elevated plus-maze test for anxiety-related behavior, (3) Pavlovian fear conditioning and extinction, and (4) behavioral responses to forced swim stress. Two C57BL/6J mice (one lowdose adolescent fluoxetine-treated, one low-dose adolescent water-treated) and seven BALB/ $\mathrm{cJ}$ (four low-dose adult fluoxetine-treated, three low-dose adult water-treated) were removed over the course of the study due to fighting or other health problems. 


\section{Novel open field}

The novel open field test was conducted as previously described (Wiedholz et al. 2008). The apparatus was a square arena $(39 \times 39 \times 35 \mathrm{~cm})$ constructed from Plexiglas evenly illuminated to $\sim 55 \mathrm{~lx}$. The mouse was placed in a corner and allowed to freely explore for $30 \mathrm{~min}$. Total distance traveled and time spent in the $(20 \times 20 \mathrm{~cm})$ center was measured using the Ethovision videotracking system (Noldus Information Technology, Leesburg, VA, USA).

\section{Elevated plus-maze}

The elevated plus-maze test was conducted as previously described (Handley and Mithani 1984; Holmes et al. 2000). The apparatus was constructed with ABS plastic and consisted of two open arms $(30 \times 5 \mathrm{~cm} ; 90 \mathrm{~lx})$ and two closed arms $(30 \times 5 \times 15 \mathrm{~cm} ; 201 \mathrm{x})$ extending from a $5 \times 5 \mathrm{~cm}$ central area and elevated $20 \mathrm{~cm}$ from the ground (San Diego Instruments, San Diego, CA, USA). A $0.5-\mathrm{cm}$ raised lip around the perimeter of the open arms prevented mice from falling off the maze. The mouse was placed in the center facing an open arm and allowed to explore the apparatus for $6 \mathrm{~min}$. Time spent in the open arms, and entries into the open and closed arms were measured by the Ethovision video-tracking system (Noldus Information Technology).

\section{Pavlovian fear conditioning and extinction}

Pavlovian fear conditioning and extinction was assessed based on methods previously described (Wellman et al. 2007; Yang et al. 2008). Mice were placed in a $27 \times 27 \times 11 \mathrm{~cm}$ chamber with transparent walls and a metal rod floor. To provide a distinctive olfactory environment, the chamber was cleaned between subjects with a 79\% EtOH/20\% water/1\% vanilla extract solution. After a 180 -s acclimation period, the mouse received three pairings (60-120 s interval after each pairing) of an auditory tone (30 s, $80 \mathrm{~dB}$, white noise) and footshock ( $2 \mathrm{~s}, 0.6 \mathrm{~mA}$ scrambled footshock), in which the shock was presented during the last $2 \mathrm{~s}$ of the tone. The presentation of stimuli was controlled by the Med Associates Freeze Monitor system (Med Associates Incorporated, Georgia, VT, USA). Twenty-four hours later, expression of fear to the tone and subsequent within-season extinction was tested. Mice were placed in a novel context (Plexiglas cylinder with black/white-checkered walls and a solid floor, cleaned with a $1 \%$ acetic acid/99\% water solution) housed in a novel room. Following an initial 180 -s acclimation period, the mouse received $50 \times 30$-s presentations of the tone alone ( $5 \mathrm{~s}$ no-stimulus interval). Twenty-four hours later, extinction recall was probed with three tone presentations. Freezing (no visible movement except that required for respiration) to the tone was manually scored every $5 \mathrm{~s}$ and converted to a percentage ([number of freezing observations/ total number of observations] $\times 100$ ). Freezing during recall/extinction trials was averaged into $10 \times 5$ trial blocks for analysis.

\section{Behavioral and neuroendocrine response to swim stress}

The forced swim test was conducted as previously described (Boyce-Rustay and Holmes 2006; Porsolt et al. 1978). The apparatus was a transparent Plexiglas cylinder ( $20 \mathrm{~cm}$ diameter) filled halfway with water $\left(24 \pm 1^{\circ} \mathrm{C}\right)$ into which mice were gently lowered. The mouse was given a 6-min trial and returned to the home cage. The presence/absence of immobility (cessation of limb movements except minor involuntary movements of the hind limbs) was manually observed using an instantaneous sampling technique every $5 \mathrm{~s}$ during the last $4 \mathrm{~min}$ and expressed as a percentage of total observations during the period.

Thirty minutes after the end of stress, mice in the adolescent, not the adult, experiments were sacrificed via rapid cervical dislocation and decapitation to collect trunk blood. Blood samples were centrifuged at $13,000 \mathrm{rpm}$ for $30 \mathrm{~s}$. Serum was extracted and assayed for total corticosterone (bound and free) using the Coat-a-Count RIA TKRC1 kit (limit of detection: 
$5.7 \mathrm{ng} / \mathrm{ml}$; Diagnostic Products, Los Angeles, CA, USA) as previously described (BoyceRustay et al. 2007).

\section{High-performance liquid chromatography analysis of 5-HT and 5-HIAA levels}

At sacrifice for trunk blood collection, brains from mice in the adolescent experiments were removed, flash-frozen in ice-cold isopentane and stored at $-80^{\circ} \mathrm{C}$. Neurochemical analysis was performed on hippocampus and frontal cortex tissue via high-performance liquid chromatography (HPLC). Frozen samples were homogenized by ultrasonic processing in 800 $\mathrm{ml}$ of $0.1 \mathrm{M}$ perchloric acid containing $1 \% \mathrm{EtOH}$ and $0.02 \%$ ethylenediaminetetraacetic acid (EDTA) and centrifuged for $20 \mathrm{~min}$ at 3,000 $\times \mathrm{g}$. Thirty microliters of the homogenate was used for catecholamine analysis by HPLC using a Luna $5 \mu \mathrm{m} \mathrm{C18(2),} 250 \times 2.0 \mathrm{~mm}$ column (Phenomenex 00G-4252-B0, Torrance, CA, USA) held at $30^{\circ} \mathrm{C}$, a Waters Corporation (Milford, MA, USA) 717 plus autosampler at $4^{\circ} \mathrm{C}, 510$ pump at $0.4 \mathrm{ml} / \mathrm{min}$, and amperometric electrochemical detector (EiCOM CB100) set at Eox. $0.82 \mathrm{~V}$. The mobile phase contained 2.8 g 1-heptanesulfonic acid sodium salt, $0.17 \mathrm{~g}$ EDTA, $20 \mathrm{ml}$ triethylamine, dissolved in 2.21 water, $\mathrm{pH}$ adjusted to 2.5 with $13 \mathrm{ml} 85 \%$ phosphoric acid, plus $90 \mathrm{ml}$ acetonitrile. The detector output was recorded and analyzed with Waters Empower 2 Chromatography Data Software.

\section{Statistics}

The effects of treatment and strain were analyzed using analysis of variance (ANOVA), followed by Newman Keuls post hoc tests where appropriate. For fear extinction, the effects of treatment, strain, and trial block on freezing were analyzed using ANOVA with repeated measures for trial block. The effects of treatment, strain, and age on body weight were analyzed using ANOVA with repeated measures for age. Statistical significance was set at $p<0.05$.

\section{Results \\ Fluoxetine treatment}

Adolescent subjects receiving the lower concentration received fluoxetine at a dose of 9-10 $\mathrm{mg} / \mathrm{kg} /$ day over the 4-week treatment period. There was a significant effect of strain for average fluoxetine received $(F 1,18=11.16, p<0.01)$. BALB/cJ received a slightly but significantly higher dose of fluoxetine than C57BL/6J (Fig. 1b). Subjects receiving the higher concentration received fluoxetine at a dose of $17-18 \mathrm{mg} / \mathrm{kg} /$ day over the 4 -week treatment period. There was again a significant effect of strain for average fluoxetine received $(F 1,18=5.01, p<0.01)$, this time due to a higher dose in C57BL/6J than BALB/cJ (Fig. 1b). Control mice drinking water did not show strain differences in either the lower or higher concentration experiments (data not shown). Neither concentration of fluoxetine treatment affected growth curves during the adolescent period in either strain, although there was a significant strain $\times$ age interaction effect on body weight cohort due to higher initial body weights in BALB/cJ than C57BL/6J in the lower $(F 3,108=9.52, p<0.01$, Fig. 1c), but not the higher concentration (Fig. 1d) experiment. Both the higher and lower doses are sufficient to produce brain concentrations in the clinical range (Ansorge et al. 2004;Dulawa et al. 2004) and induce acute behavioral effects in adult mice (Holmes and Rodgers 2003).

Adult subjects receiving the lower fluoxetine concentration received a dose of $8-12 \mathrm{mg} / \mathrm{kg} /$ day over the 4-week treatment period. There was a significant effect of strain for average fluoxetine received $(F 1,15=8.14, p<0.05)$. In this adult cohort, $\mathrm{BALB} / \mathrm{cJ}$ received a significantly higher dose of fluoxetine than C57BL/6J (Table 1). BALB/cJ also drank more water than C57BL/6J $(F 1,15=9.45, p<0.01$; Table 1$)$. Body weights increased more quickly in $\mathrm{C} 57 \mathrm{BL} / 6 \mathrm{~J}$ than $\mathrm{BALB} / \mathrm{cJ}$ across the treatment period (strain $\times$ week interaction: $F 3,87=14.08$, $p<0.01$ ) but did not differ as a function of treatment (weights not shown). 


\section{Novel open field}

For the adolescents receiving the lower dose of fluoxetine, there was a significant effect of strain for total distance $(F 1,36=48.17, p<0.01)$ and percent center time $(F 1,36=60.63, p<0.01)$, but no effect of treatment and no treatment $\times$ strain interaction for either measure. BALB/cJ traveled less far (Fig. 2a) and spent less time in the center of the open field (Fig. 2b) than C57BL/6J, regardless of treatment.

For the adolescents receiving the higher dose of fluoxetine, there was a significant effect of strain for total distance $(F 1,36=37.34, p<0.01)$ and percent center time $(F 1,36=59.24, p<0.01)$, but no effect of treatment and no treatment $\times$ strain interaction for either measure. BALB/cJ again traveled less far (Fig. 2c) and spent less time in the center (Fig. 2d) than C57BL/6J, regardless of treatment.

For the adult treated mice, there was a significant effect of strain for total distance $(F 1,29=18.47, p<0.01)$ and percent center time $(F 1,29=44.42, p<0.01)$, but no effect of treatment and no treatment $\times$ strain interaction for either measure. As in the adolescent cohorts, $\mathrm{BALB} / \mathrm{cJ}$ traveled less far and spent less time in the center than C57BL/6J, irrespective of treatment (Table 1).

\section{Elevated plus-maze}

For the adolescents receiving the lower dose of fluoxetine, there was a significant effect of strain for open arm time $(F 1,36=56.58, p<0.01)$ and open arm entries $(F 1,36=72.97, p<0.01)$ but not closed arm entries, but no effect of treatment and no treatment $\times$ strain interaction for any measure. BALB/cJ spent less time in the open arms (Fig. 3a) and made fewer open arm entries (Fig. 3b) than C57BL/6J regardless of treatment, while closed arm entries did not differ betweens strains (Fig. 3c).

For the adolescents receiving the higher dose of fluoxetine, there was a significant effect of strain for open arm time $(F 1,36=34.38, p<0.01)$ and open arm entries $(F 1,36=85.56, p<0.01)$ but not closed arm entries, and no effect of treatment and no treatment $\times$ strain interaction for either measure. Again, BALB/cJ spent less time in the open arms (Fig. 3d) and made fewer open arm entries (Fig. 3e) than C57BL/6J regardless of treatment, and closed arm entries did not differ betweens strains (Fig. 3f).

Results were similar for the adult treated mice. There was a significant effect of strain for open arm time $(F 1,29=25.70, p<0.01)$ and open arm entries $(F 1,29=51.12, p<0.01)$ but not closed arm entries, but no effect of treatment and no treatment $\times$ strain interaction for either measure. $\mathrm{BALB} / \mathrm{cJ}$ spent less time in the open arms and made fewer open arm entries than C57BL/6J regardless of treatment. Closed arm entries was no different betweens strains (Table 1).

\section{Pavlovian fear conditioning and extinction}

For the adolescents receiving the lower dose of fluoxetine, there was a significant effect of strain $(F 1,34=7.68, p<0.01)$, but no effect of treatment or strain $\times$ interactions for freezing during conditioning. This was due to higher freezing in C57BL/6J than BALB/cJ. For freezing during extinction, there was no treatment $\times$ strain $\times$ trial block interaction, but there was a significant effect of strain $(F 1,34=19.31, p<0.01)$ and a significant strain $\times$ trial block interaction $(F 9,306=6.03, p<0.01)$. Examining the effects of treatment in each strain revealed a significant treatment $\times$ trial block interaction in C57BL/6J $(F 9,144=35.14, p<0.01)$ and a significant effect of trial block alone $(F 9,162=15.77, p<0.01)$ in BALB/cJ (Fig. 4a, left panel). Fluoxetine-treated C57BL/6J mice froze significantly less during the first trial block of extinction than vehicle-treated controls (Fig. 4a, right panel). There were no effects of treatment or strain on freezing during extinction recall (data not shown). C57BL/6J generally showed 
more freezing than BALB/cJ during conditioning and fear recall/extinction, regardless of treatment.

For the adolescents receiving the higher dose of fluoxetine, there was a significant effect of strain $(F 1,36=33.17, p<0.01)$, but no effect of treatment and strain $\times$ treatment interaction, for freezing during conditioning. C57BL/6J froze more than BALB/cJ during conditioning. For freezing during extinction, there was no treatment $\times$ strain $\times$ trial block interaction, but there was a significant effect of strain $(F 1,36=31.72, p<0.01)$ and a significant strain $\times$ trial block interaction $(F 9,324=11.38, p<0.01)$. Examining the effects of treatment in each strain found no significant effects of treatment for either strain, but did indicate a significant effect of trial block in BALB/cJ $(F 9,162=5.82, p<0.01$; Fig. 4b, left panel $)$ and C57BL/6J $(F 9,162=44.69$, $p<0.01$; Fig. $4 \mathrm{~b}$, right panel). There were no effects of treatment or strain on freezing during extinction recall (data now shown). C57BL/6J showed significantly more freezing than BALB/ cJ during fear recall/extinction. C57BL/6J again generally showed more freezing than BALB/ cJ during conditioning and recall/extinction, regardless of treatment.

For the adult treated mice, there was a significant treatment $\times$ strain interaction $(F 3,87=5.18$, $p<0.01$ ) for freezing during conditioning due to higher freezing to the third tone in C57BL/6J relative to BALB/cJ. For freezing during extinction, there was no treatment $\times$ strain $\times$ trial block interaction, but there was a significant strain $\times$ trial block interaction $(F 9,261=1.97$, $p<0.05)$. Examining the effects of treatment in each strain revealed no significant effects of treatment for either strain, but a significant effect of trial block in BALB/cJ $(F 9,99=8.14$, $p<0.01)$ and C57BL/6J $(F 9,162=22.59, p<0.01)$. There were no effects of strain for freezing during extinction, and no treatment or strain effects for freezing during extinction recall (data not shown).

\section{Behavioral and neuroendocrine response to swim stress}

For the adolescents receiving the lower dose of fluoxetine, there was a significant effect of strain $(F 1,34=4.73, p<0.05)$ but not treatment and no treatment $\times$ strain interaction for immobility. BALB/cJ showed more immobility than C57BL/6J regardless of treatment (Fig. $5 a)$. There was no effect of treatment or strain or a treatment $\times$ strain interaction for corticosterone levels after stress (water-treated BALB/cJ $=273 \pm 12 \mathrm{ng} / \mathrm{mL}$, fluoxetine-treated $\mathrm{BALB} / \mathrm{cJ}=262 \pm 27$, water-treated C57BL $/ 6 \mathrm{~J}=230 \pm 13 \mathrm{ng} / \mathrm{mL}$, fluoxetine-treated C57BL/ $6 \mathrm{~J}=279 \pm 11, n=5-7)$.

For the adolescents receiving the higher dose of fluoxetine, there was no significant effect of strain or treatment and no interaction for immobility (Fig. 5b). There was a significant effect of strain $(F 1,27=4.88, p<0.05)$ but not treatment and no treatment $\times$ strain interaction for corticosterone levels after stress. Data collapsed across treatment found no significant effect strain difference (water-treated BALB/cJ $=337 \pm 16 \mathrm{ng} / \mathrm{mL}$, fluoxetine-treated $\mathrm{BALB} / \mathrm{cJ}=280$ \pm 20 , water-treated C57BL/6J=275 $\pm 11 \mathrm{ng} / \mathrm{mL}$, fluoxetine-treated C57BL/6J=260 $\pm 27, n=6-9$ ).

For the adult treated mice, there was also no significant effect of strain or treatment, nor an interaction, for immobility (Table 1).

\section{HPLC analysis of 5-HT and 5-HIAA levels}

For the adolescents receiving the lower dose of fluoxetine, there was no significant main effect of treatment and no treatment $\times$ strain interaction for 5-HT or 5-HIAA levels in frontal cortex or hippocampus (Table 2). There was a significant main effect of strain for hippocampal 5HIAA, due to lower hippocampal levels in BALB/cJ than C57BL/6J $(F 1,34=5.06, p<0.05)$.

For the adolescents receiving the higher dose of fluoxetine, there was no effect of treatment or strain for 5-HT or 5-HIAA in frontal cortex. There was a significant treatment $\times$ strain 
interaction for 5-HT $(F 1,35=5.02, p<0.05)$ and 5-HIAA $(F 1,35=8.37, p<0.01)$ in hippocampus. Post hoc tests showed that fluoxetine-treated BALB/cJ had lower levels of hippocampal 5HIAA, but not 5-HT, compared to vehicle-treated BALB/cJ, while a trend for the opposite pattern was seen in C57BL/6J ( $p=0.052$; Table 2$)$. Data collapsed across treatment indicated less hippocampal 5-HIAA $(p<0.01)$ and 5-HT $(p<0.01)$ levels in BALB/cJ relative to C57BL/ $6 \mathrm{~J}$.

\section{Discussion}

The main finding of the present study was that treatment with clinically relevant doses of fluoxetine throughout the mouse developmental period corresponding to human adolescence did not cause abnormalities on assays for fear-, anxiety- and stress-related phenotypes when mice were tested drug-free in adulthood. Specifically, chronic treatment with fluoxetine during mouse adolescence (3-7 weeks of age) did not produce robust alterations in adult anxietyrelated behaviors as measured in the novel open field and elevated plus-maze test or behavioral or neuroendocrine response to forced swim stress. Although adolescent fluoxetine-treated mice showed reduced conditioned fear when tested as adults, echoing a previous reports in rats while on treatment (Burghardt et al. 2004), this was only seen in one strain (C57BL/6J) and at one fluoxetine dose and, therefore, may not be a reliable effect of treatment.

The absence of long-lasting effects of fluoxetine treatment during mouse adolescence extends and contrasts with previous work showing that treatment of mice with fluoxetine during the early postnatal period (4-21 days of age) causes increased anxiety-like behavior in adulthood (Ansorge et al. 2008, 2004), as well as some but not all studies showing that neonatal antidepressant treatment increases anxiety- and depression-related behavior in rats (Andersen et al. 2002; Feng et al. 2001; Hansen et al. 1997; Hilakivi and Hilakivi 1987; Maciag et al. 2006a, 2006b; Prathiba et al. 1995; Velazquez-Moctezuma and Diaz Ruiz 1992; Yoo et al. 2000). Present findings are generally consistent with Bhansali et al.'s finding that BALB/cJ mice treated with fluoxetine from approximately 4-9 weeks of age did not show any obvious baseline difference in forced swim test behavior (Bhansali et al. 2007). It should be noted that neither Bhansali et al. nor our study undertook a direct replication of the pro-anxiety-like effects of preadolescent fluoxetine treatment under the same test conditions that were insensitive to adolescent treatment. Nonetheless, taken together, these data support a working model in which the early postnatal life represents a critical window of vulnerability to the adverse effects of fluoxetine treatment, while the adolescent period, at least in the mouse, is relatively insensitive to long-lasting effects of this treatment. While the neuronal basis of this ontogenic pattern of sensitivity remains to be determined, it is noteworthy that the early postnatal time frame corresponds to a period of forebrain innervation by mature serotonergic neurons and a transient peak in levels of endogenous 5-HT (Hohmann et al. 1988; Lidov and Molliver 1982a, 1982b; Mitchell et al. 1990).

A number of studies have shown that the BALB/c and C57BL/6 strains fall on the high and low ends of the spectrum of trait anxiety-like behavior and stress-reactivity, respectively, and that $\mathrm{BALB} / \mathrm{c}$ are also relatively more sensitive to the behavioral actions of antidepressants (Anisman et al. 2001; Belzung and Griebel 2001; Dulawa et al. 2004; Holmes et al. 2005). Replicating these phenotypic differences under our laboratory conditions, BALB/cJ showed higher levels of anxiety-like behavior in the elevated plus-maze (i.e., increased open arm avoidance, but normal locomotor activity). Levels of exploratory activity in the novel open field were also lower in BALB/cJ than C57BL/6J. Given the concomitant increase in avoidance of the open field center, together with increased anxiety-like behavior (but normal closed arm entries) in the elevated plus-maze, this is likely a further reflection of increased anxiety in the $\mathrm{BALB} / \mathrm{cJ}$ strain rather than a locomotor deficit (Cryan and Holmes 2005). In the forced swim test, BALB/cJ showed slightly higher immobility than C57BL/6J in one experiment, but this 
was not a consistent difference across experiments. In addition, BALB/cJ generally showed less conditioned fear than C57BL/6J (as evidenced by lesser freezing either during conditioning or the first trial block of extinction), as previously reported (Bolivar et al. 2001; Bothe et al. 2005). Although BALB/c show slightly more age-related hearing loss than C57BL/6, this is unlikely to be a factor at the age tested (Willott et al. 1998) and therefore, the lesser fear conditioning appears to a genuine dissociation from the increased anxiety-like behavior in this strain.

The absence of adolescent fluoxetine treatment effects is notable against the background of these marked strain differences in "trait emotionality." These negative effects cannot be explained by an idiosyncratic resistance of the C57BL/6J strain to the drug's effects per se. Moreover, the absence of adolescent fluoxetine effects across two strains representing high and low ends of the range of murine anxiety- and stress-related behaviors supports the generalizability of the data. An important caveat, however, is that it is conceivable that high basal levels of anxiety-/fear-/stress-related behaviors in BALB/cJ could have masked further increases in these behaviors due to fluoxetine. This possibility should not be discounted for anxiety-like behaviors in the novel open field and elevated plus-maze, where a "floor" effect in BALB/cJ may have prevented the detection of treatment-related increases in this behavior. On the other hand, for the depression- and stress-related measures, there appeared to be sufficient range to observe fluoxetine-induced effects in $\mathrm{BALB} / \mathrm{cJ}$, and yet effects were still not observed.

Previous work has found that low levels of 5-HT and 5-HIAA in BALB/cJ relative to C57BL/ $6 \mathrm{~J}$ are linked to a loss-of-function polymorphism in the gene encoding the 5-HT synthesizing enzyme, tryptophan hydroxylase 2 (Holmes 2008; Zhang et al. 2004). Current data showed that BALB/cJ had lower levels of 5-HT and/or its major metabolite, 5-HIAA, relative to C57BL/6J. Differences were found in the hippocampus but not frontal cortex, which would be consistent with the putative contribution of the hippocampus in mediating emotional behaviors and antidepressant effects (Schmidt and Duman 2007; but see (Holick et al. 2007).

Interestingly, BALB/cJ receiving the higher fluoxetine dose during adolescence had significantly lower hippocampal levels of 5-HIAA than vehicle-treated counterparts when assayed approximately 8 weeks later in adulthood, whereas C57BL/6J showed a trend in the opposite direction. The latter observation is consistent with the finding that chronic fluoxetine treatment in adult NMRI mice is associated with a significant increase in 5-HT turnover in hippocampus and frontal cortex 1 week posttreatment (Stenfors and Ross 2002). On the other hand, the reduction in $\mathrm{BALB} / \mathrm{cJ}$ is unexpected and hints at a lasting adaptation of the hippocampal serotonin system. This is noteworthy in the context of previous evidence that $\mathrm{BALB} / \mathrm{cJ}$ is relatively insensitive, compared to $\mathrm{C} 57 \mathrm{BL} / 6 \mathrm{~J}$, to adult fluoxetine treatment in certain behavioral assays (e.g., Dulawa et al. 2004; Lucki et al. 2001). It must be reiterated, however, that any such change was not detectable at the behavioral level.

The finding that adolescent fluoxetine treatment did not alter adult behaviors could be construed as tentative evidence that treating children and adolescents with fluoxetine might not produce lasting adverse effects. However, there are a number of important issues to consider in making this generalization. First, the present study examined the effects of one antidepressant, fluoxetine, on the basis of earlier work showing that this compound increased emotion-related behaviors in mice when administered during the early postnatal period. It therefore remains to be seen whether other antidepressants, either within the same SRI class or other classes, would produce the same effects, although recent data demonstrating that early postnatal fluoxetine is more effective than desipramine or citalopram in affecting anxiety-like behavior argues against this possibility (Ansorge et al. 2008). Nonetheless, it would be important to examine the effects of other antidepressants during rodent adolescence, 
particularly in light of evidence that fluoxetine has a relatively favorable profile in adolescents (humans) in comparison to certain other antidepressants (Whittington et al. 2004).

A second caveat relates to the fact that the aim of the present study was to test whether fluoxetine treatment during adolescence had long lasting effects (e.g., neural circuit alterations (Hariri and Holmes 2006)) when probed for in (drug-free) adulthood. For this reason, and in view of the long half-life of fluoxetine, behavioral testing commenced after a long washout period of 3 weeks posttreatment. This experimental design is akin to studies that have demonstrated lasting effects of early postnatal treatment or gene mutation on adult behaviors (Alexandre et al. 2006; Ansorge et al. 2004; Gross et al. 2002). We showed that mice receiving chronic fluoxetine treatment had no residual effect of the drug when tested after a similar 3-week washout period. However, a question that our data does not address is whether significant behavioral abnormalities are manifested during the acute withdrawal period and whether these might be more or less prominent in adolescents than adults.

A third and final issue is that while current data speak to an absence of effects of adolescent fluoxetine treatment on a variety of standard measures of anxiety-/fear-/stress-related behaviors, it would be premature to exclude potential effects of the same treatment on other behavioral processes. In this context, increased suicidal ideation, aggression, and impulsivity are reported to be abnormal in a subpopulation of SRI-treated children (Hammad et al. 2006; Usala et al. 2007; Whittington et al. 2004). It will therefore be of importance to examine the effects of adolescent fluoxetine treatment on phenotypic measures such as conspecific aggression and executive functions (e.g., see (LaRoche and Morgan 2007).

In summary, the present study found no evidence that fluoxetine treatment throughout the adolescent period causes increases in fear-, anxiety- or stress-related endpoints in two genetic strains of mice differing in trait anxiety- and stress-related behavior and sensitivity to fluoxetine. While further work will be needed to extend these data to other behavioral domains, present findings contribute to the ongoing debate over the risks and benefits of antidepressant treatment in children and adolescents (Gibbons et al. 2007).

\section{Acknowledgements}

The research is supported by the Intramural Research Program of the National Institute of Alcohol Abuse and Alcoholism (Z01-AA000411) and National Institute on Mental Health (Z01-MH002784). The authors declare no financial conflicts of interest.

\section{References}

Alexandre C, Popa D, Fabre V, Bouali S, Venault P, Lesch KP, Hamon M, Adrien J. Early life blockade of 5-hydroxytryptamine $1 \mathrm{~A}$ receptors normalizes sleep and depression-like behavior in adult knockout mice lacking the serotonin transporter. J Neurosci 2006;26:5554-5564. [PubMed: 16707806]

Andersen SL, Dumont NL, Teicher MH. Differences in behavior and monoamine laterality following neonatal clomipramine treatment. Dev Psychobiol 2002;41:50-57. [PubMed: 12115290]

Anisman H, Hayley S, Kelly O, Borowski T, Merali Z. Psychogenic, neurogenic, and systemic stressor effects on plasma corticosterone and behavior: mouse strain-dependent outcomes. Behav Neurosci 2001;115:443-454. [PubMed: 11345969]

Ansorge MS, Zhou M, Lira A, Hen R, Gingrich JA. Early-life blockade of the 5-HT transporter alters emotional behavior in adult mice. Science 2004;306:879-881. [PubMed: 15514160]

Ansorge MS, Hen R, Gingrich JA. Neurodevelopmental origins of depressive disorders. Curr Opin Pharmacol 2007;7:8-17. [PubMed: 17188022]

Ansorge MS, Morelli E, Gingrich JA. Inhibition of serotonin but not norepinephrine transport during development produces delayed, persistent perturbations of emotional behaviors in mice. J Neurosci 2008;28:199-207. [PubMed: 18171937] 
Belzung C, Griebel G. Measuring normal and pathological anxiety-like behaviour in mice: a review. Behav Brain Res 2001;125:141-149. [PubMed: 11682105]

Bhansali P, Dunning J, Singer SE, David L, Schmauss C. Early life stress alters adult serotonin 2C receptor pre-mRNA editing and expression of the alpha subunit of the heterotrimeric G-protein G q. J Neurosci 2007;27:1467-1473. [PubMed: 17287521]

Bolivar VJ, Pooler O, Flaherty L. Inbred strain variation in contextual and cued fear conditioning behavior. Mamm Genome 2001;12:651-656. [PubMed: 11471061]

Bothe GW, Bolivar VJ, Vedder MJ, Geistfeld JG. Behavioral differences among fourteen inbred mouse strains commonly used as disease models. Comp Med 2005;55:326-334. [PubMed: 16158908]

Boyce-Rustay JM, Holmes A. Genetic inactivation of the NMDA receptor NR2A subunit has anxiolyticand antidepres-sant-like effects in mice. Neuropsychopharmacology 2006;31:2405-2414. [PubMed: 16482087]

Boyce-Rustay JM, Cameron HA, Holmes A. Chronic swim stress alters sensitivity to acute behavioral effects of ethanol in mice. Physiol Behav 2007;91:77-86. [PubMed: 17363014]

Burghardt NS, Sullivan GM, McEwen BS, Gorman JM, LeDoux JE. The selective serotonin reuptake inhibitor citalopram increases fear after acute treatment but reduces fear with chronic treatment: a comparison with tianeptine. Biol Psychiatry 2004;55:1171-1178. [PubMed: 15184036]

Cryan JF, Holmes A. The ascent of mouse: advances in modelling human depression and anxiety. Nat Rev Drug Discov 2005;4:775-790. [PubMed: 16138108]

Dohler KD, Wuttke W. Changes with age in levels of serum gonadotropins, prolactin and gonadal steroids in prepubertal male and female rats. Endocrinology 1975;97:898-907. [PubMed: 1193012]

Dulawa SC, Holick KA, Gundersen B, Hen R. Effects of chronic fluoxetine in animal models of anxiety and depression. Neuropsychopharmacology 2004;29:1321-1330. [PubMed: 15085085]

Feng P, Ma Y, Vogel GW. The critical window of brain development from susceptive to insusceptive. Effects of clomipramine neonatal treatment on sexual behavior. Brain Res Dev Brain Res 2001;129:107-110.

Gaspar P, Cases O, Maroteaux L. The developmental role of serotonin: news from mouse molecular genetics. Nat Rev Neurosci 2003;4:1002-1012. [PubMed: 14618156]

Gibbons RD, Brown CH, Hur K, Marcus SM, Bhaumik DK, Erkens JA, Herings RM, Mann JJ. Early evidence on the effects of regulators' suicidality warnings on SSRI prescriptions and suicide in children and adolescents. Am J Psychiatry 2007;164:1356-1363. [PubMed: 17728420]

Gross C, Hen R. The developmental origins of anxiety. Nat Rev Neurosci 2004;5:545-552. [PubMed: 15208696]

Gross C, Zhuang X, Stark K, Ramboz S, Oosting R, Kirby L, Santarelli L, Beck S, Hen R. Serotonin1A receptor acts during development to establish normal anxiety-like behaviour in the adult. Nature 2002;416:396-400. [PubMed: 11919622]

Hammad TA, Laughren T, Racoosin J. Suicidality in pediatric patients treated with antidepressant drugs. Arch Gen Psychiatry 2006;63:332-339. [PubMed: 16520440]

Handley SL, Mithani S. Effects of alpha-adrenoceptor agonists and antagonists in a maze-exploration model of 'fear'-motivated behaviour. Naunyn Schmiedebergs Arch Pharmacol 1984;327:1-5. [PubMed: 6149466]

Hansen HH, Sanchez C, Meier E. Neonatal administration of the selective serotonin reuptake inhibitor Lu 10-134-C increases forced swimming-induced immobility in adult rats: a putative animal model of depression? J Pharmacol Exp Ther 1997;283:1333-1341. [PubMed: 9400008]

Hariri AR, Holmes A. Genetics of emotional regulation: the role of the serotonin transporter in neural function. Trends Cogn Sci 2006;10:182-191. [PubMed: 16530463]

Hefner K, Holmes A. An investigation of the behavioral actions of ethanol across adolescence in mice. Psychopharmacology (Berl) 2007a;191:311-22. [PubMed: 17206494]

Hefner K, Holmes A. Ontogeny of fear-, anxiety- and depression-related behavior across adolescence in C57BL/6J mice. Behav Brain Res 2007b;176:210-215. [PubMed: 17098297]

Hilakivi LA, Hilakivi I. Increased adult behavioral 'despair' in rats neonatally exposed to desipramine or zimeldine: an animal model of depression? Pharmacol Biochem Behav 1987;28:367-369. [PubMed: 2960986] 
Hohmann CF, Hamon R, Batshaw ML, Coyle JT. Transient postnatal elevation of serotonin levels in mouse neocortex. Brain Res 1988;471:163-166. [PubMed: 2464412]

Holick KA, Lee DC, Hen R, Dulawa SC. Behavioral Effects of Chronic Fluoxetine in BALB/cJ Mice Do Not Require Adult Hippocampal Neurogenesis or the Serotonin 1A Receptor. Neuropsychopharmacology 2007;33:406-417. [PubMed: 17429410]

Holmes A. Genetic variation in cortico-amygdala serotonin function and risk for stress-related disease. Neurosci Biobehav Rev. 200810.1016/j.neurobiorev.2008.03.006

Holmes A, Rodgers RJ. Prior exposure to the elevated plus-maze sensitizes mice to the acute behavioral effects of fluoxetine and phenelzine. Eur J Pharmacol 2003;459:221-230. [PubMed: 12524150]

Holmes A, Parmigiani S, Ferrari PF, Palanza P, Rodgers RJ. Behavioral profile of wild mice in the elevated plus-maze test for anxiety. Physiol Behav 2000;71:509-516. [PubMed: 11239669]

Holmes A, le Guisquet AM, Vogel E, Millstein RA, Leman S, Belzung C. Early life genetic, epigenetic and environmental factors shaping emotionality in rodents. Neurosci Biobehav Rev 2005;29:13351346. [PubMed: 16095695]

LaRoche RB, Morgan RE. Adolescent fluoxetine exposure produces enduring, sex-specific alterations of visual discrimination and attention in rats. Neurotoxicol Teratol 2007;29:96-107. [PubMed: 17182216]

Lidov HG, Molliver ME. An immunohistochemical study of serotonin neuron development in the rat: ascending pathways and terminal fields. Brain Res Bull 1982a;8:389-430. [PubMed: 6178481]

Lidov HG, Molliver ME. Immunohistochemical study of the development of serotonergic neurons in the rat CNS. Brain Res Bull 1982b;9:559-604. [PubMed: 6756556]

Lucki I, Dalvi A, Mayorga AJ. Sensitivity to the effects of pharmacologically selective antidepressants in different strains of mice. Psychopharmacology (Berl) 2001;155:315-322. [PubMed: 11432695]

Maciag D, Simpson KL, Coppinger D, Lu Y, Wang Y, Lin RC, Paul IA. Neonatal antidepressant exposure has lasting effects on behavior and serotonin circuitry. Neuropsychopharmacology 2006a;31:47-57. [PubMed: 16012532]

Maciag D, Williams L, Coppinger D, Paul IA. Neonatal citalopram exposure produces lasting changes in behavior which are reversed by adult imipramine treatment. Eur J Pharmacol 2006b;532:265-269. [PubMed: 16483567]

Millstein RA, Holmes A. Effects of repeated maternal separation on anxiety- and depression-related phenotypes in different mouse strains. Neurosci Biobehav Rev 2007;31:3-17. [PubMed: 16950513]

Mitchell JB, Iny LJ, Meaney MJ. The role of serotonin in the development and environmental regulation of type II corticosteroid receptor binding in rat hippocampus. Brain Res Dev Brain Res 1990;55:231235.

Porsolt RD, Bertin A, Jalfre M. Behavioural despair" in rats and mice: strain differences and the effects of imipramine. Eur J Pharmacol 1978;51:291-294. [PubMed: 568552]

Prathiba J, Kumar KB, Karanth KS. Effects of neonatal clomipramine on cholinergic receptor sensitivity and passive avoidance behavior in adult rats. J Neural Transm Gen Sect 1995;100:93-99. [PubMed: 8962688]

Schmidt HD, Duman RS. The role of neurotrophic factors in adult hippocampal neurogenesis, antidepressant treatments and animal models of depressive-like behavior. Behav Pharmacol 2007;18:391-418. [PubMed: 17762509]

Spear LP, Brake SC. Periadolescence: age-dependent behavior and psychopharmacological responsivity in rats. Dev Psychobiol 1983;16:83-109. [PubMed: 6339302]

Stenfors C, Ross SB. Evidence for involvement of 5-hydroxytryptamine(1B) autoreceptors in the enhancement of serotonin turnover in the mouse brain following repeated treatment with fluoxetine. Life Sci 2002;71:2867-2880. [PubMed: 12377268]

Usala T, Clavenna A, Zuddas A, Bonati M. Randomised controlled trials of selective serotonin reuptake inhibitors in treating depression in children and adolescents: a systematic review and meta-analysis. Eur Neuropsychopharmacol 2008;18:62-73. [PubMed: 17662579]

Velazquez-Moctezuma J, Diaz Ruiz O. Neonatal treatment with clomipramine increased immobility in the forced swim test: an attribute of animal models of depression. Pharmacol Biochem Behav 1992;42:737-739. [PubMed: 1513855] 
Wellman CL, Izquierdo A, Garret JE, Martin KP, Carroll J, Millstein R, Lesch KP, Murphy DL, Holmes A. Impaired stress-coping and fear extinction and abnormal corticolimbic morphology in serotonin transporter knock-out mice. J Neurosci 2007;27:684-691. [PubMed: 17234600]

Whitaker-Azmitia PM, Druse M, Walker P, Lauder JM. Serotonin as a developmental signal. Behav Brain Res 1996;73:19-29. [PubMed: 8788472]

Whittington CJ, Kendall T, Fonagy P, Cottrell D, Cotgrove A, Boddington E. Selective serotonin reuptake inhibitors in childhood depression: systematic review of published versus unpublished data. Lancet 2004;363:1341-1345. [PubMed: 15110490]

Wiedholz LM, Owens WA, Horton RE, Feyder M, Karlsson RM, Hefner K, Sprengel R, Celikel T, Daws LC, Holmes A. Mice lacking the AMPA GluR1 receptor exhibit striatal hyper-dopaminergia and 'schizophrenia-related' behaviors. Mol Psychiatry 2008;13:631-640. [PubMed: 17684498]

Willott JF, Turner JG, Carlson S, Ding D, Seegers Bross L, Falls WA. The BALB/c mouse as an animal model for progressive sensorineural hearing loss. Hear Res 1998;115:162-174. [PubMed: 9472745]

Yang RJ, Mozhui K, Karlsson RM, Cameron HA, Williams RW, Holmes A. Variation in mouse basolateral amygdala volume is associated with differences in stress reactivity and fear learning. Neuropsychopharmacology. 200810.1038/sj.npp.1301665

Yoo HS, Bunnell BN, Crabbe JB, Kalish LR, Dishman RK. Failure of neonatal clomipramine treatment to alter forced swim immobility: chronic treadmill or activity-wheel running and imipramine. Physiol Behav 2000;70:407-411. [PubMed: 11006441]

Zhang X, Beaulieu JM, Sotnikova TD, Gainetdinov RR, Caron MG. Tryptophan hydroxylase-2 controls brain serotonin synthesis. Science 2004;305:217. [PubMed: 15247473] 
a Age (weeks)
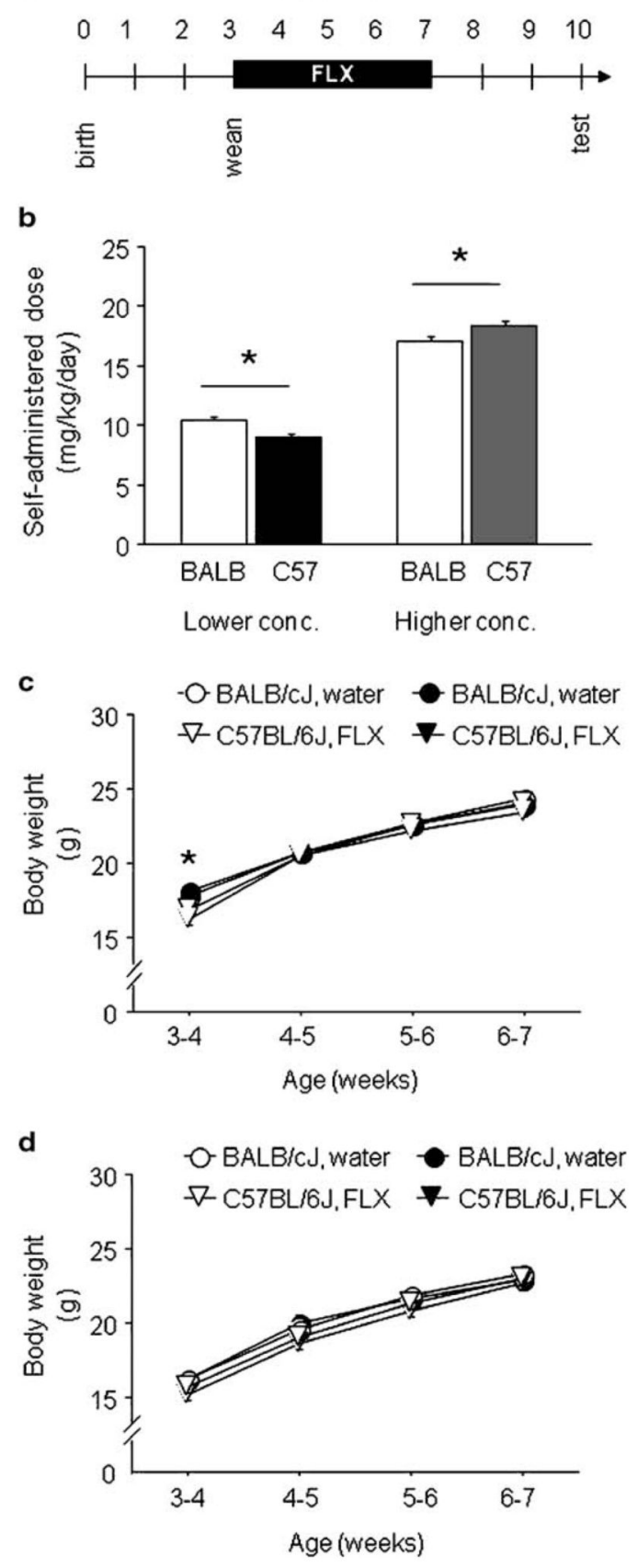

Fig. 1.

Fluoxetine dosing and growth curves. a Schematic depicting fluoxetine treatment during adolescence and testing in adulthood. b Average dose over the 4-week treatment period in mice receiving a lower or higher concentration (conc.) of fluoxetine $(F L X)$. BALB/cJ $(B A L B)$ administered a higher fluoxetine dose than C57BL/6J (C57) at the lower concentration, while the opposite pattern was evident at the higher concentration. c, $\mathbf{d}$ Regardless of concentration, fluoxetine treatment did not affect adolescent growth in BALB/cJ or C57BL/6J. BALB/cJ in the lower concentration group had higher initial body weights than C57BL/6J (c). n=10/strain/ treatment/concentration. ${ }^{*} p<0.05 \mathrm{BALB} / \mathrm{cJ}$ vs. C57BL/6J. Data are means \pm SEM 

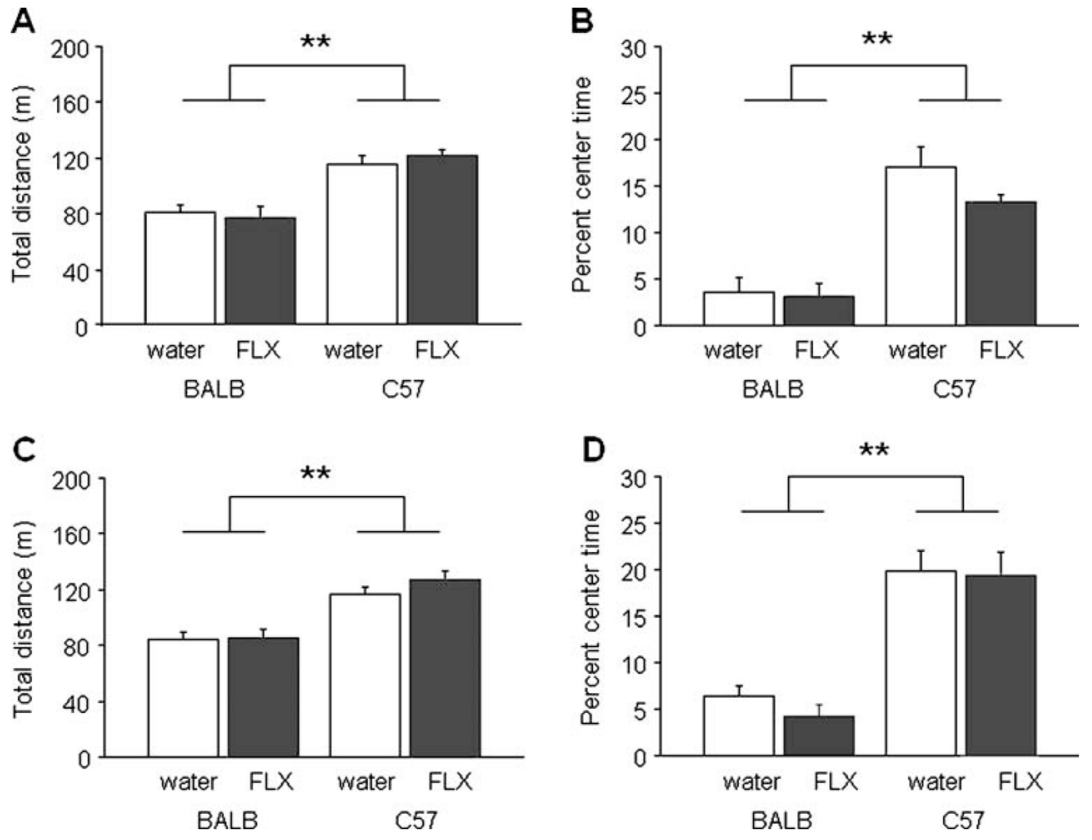

Fig. 2.

Adolescent fluoxetine treatment did not affect adult exploratory or anxiety-related behaviors in the novel open field test in either BALB/cJ or C57BL/6J mice. Total distance traveled (a) and percent time in center (b) in the novel open field was no different between mice receiving the lower dose of fluoxetine (FLX) compared to water-treated controls, regardless of strain. Total distance traveled (c) and percent center time (d) was no different between mice receiving the higher fluoxetine dose and water-treated controls, regardless of strain. BALB/cJ consistently showed less exploration and greater center avoidance than C57BL/6J. **p<0.01 BALB/cJ vs. C57BL/6J. $n=10 /$ strain/treatment/dose. Data are means \pm SEM 
A
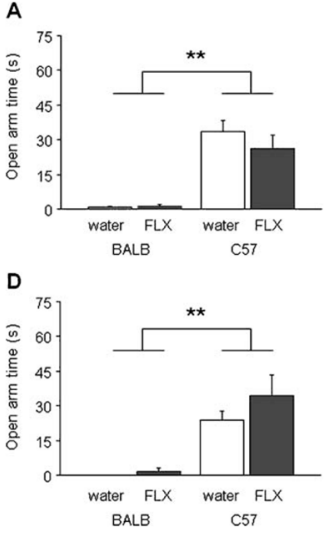

B

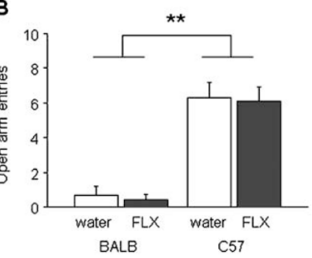

E

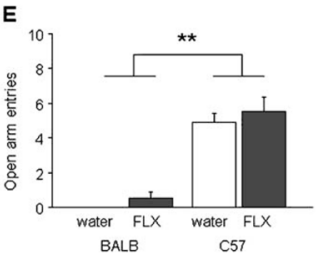

C
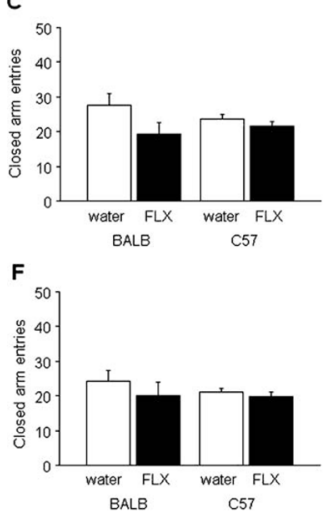

Fig. 3.

Adolescent fluoxetine treatment did not affect anxiety-related behaviors in the elevated plusmaze test in either BALB/cJ or C57BL/6J mice. Open arm exploration (a), open arm entries (b), and closed arm entries (c) in the elevated plus maze was no different between mice receiving the lower dose of fluoxetine $(F L X)$ relative to water-treated controls, irrespective of strain. Open arm exploration (d), open arm entries (e), and closed arm entries (f) was no different between mice receiving the higher fluoxetine dose compared to water-treated controls, irrespective of strain. BALB/cJ consistently showed greater open arm avoidance than C57BL/6J. ${ }^{* *} p<0.01 \mathrm{BALB} / \mathrm{cJ}$ vs. C57BL/6J. $n=10 /$ strain/treatment/dose. Data are means \pm SEM 

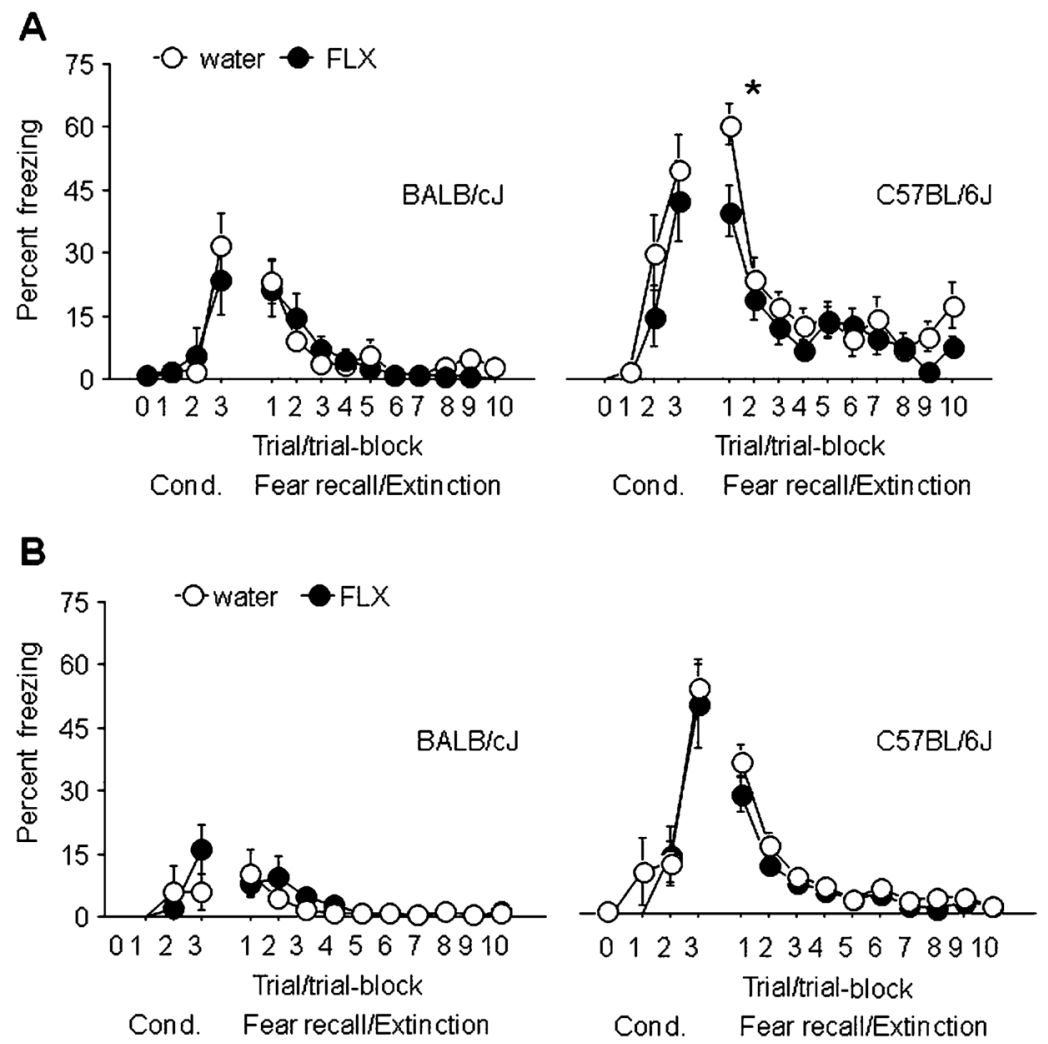

Fig. 4.

Effects of adolescent fluoxetine treatment on adult fear conditioning and extinction in BALB/ $\mathrm{cJ}$ and $\mathrm{C} 57 \mathrm{BL} / 6 \mathrm{~J}$ mice. There were no differences in freezing during conditioning, extinction, or extinction recall between BALB/cJ mice receiving the lower dose (a, left panel) or higher dose (b, left panel) of fluoxetine $(F L X)$ relative to water-treated controls. C57BL/6J mice treated with the lower dose (a, right panel) but not higher dose (b, right panel) of fluoxetine showed normal freezing during conditioning but decreased freezing during fear recall, compared to water-treated controls, while rates of extinction were not affected by fluoxetine treatment. $n=8-10 /$ strain/treatment. ${ }^{*} p<0.05$ same trial block in water-treated C57BL/6J mice. Data are means \pm SEM 

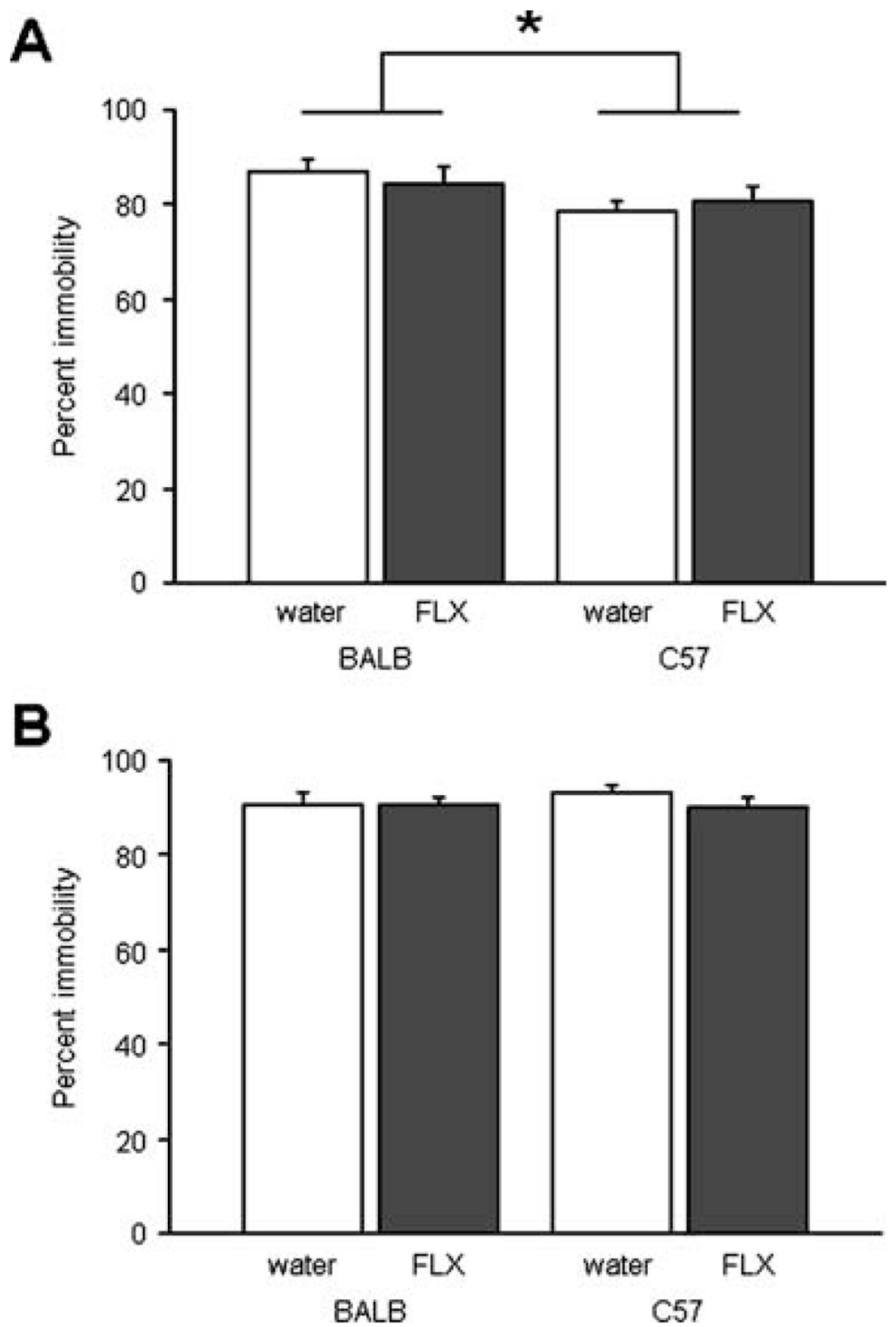

Fig. 5.

Adolescent fluoxetine treatment did not affect behavioral responses to swim stress in either $\mathrm{BALB} / \mathrm{cJ}$ or C57BL/6J mice. Percent time immobile was no different between mice receiving the lower-dose (a) or higher dose (b) of fluoxetine ( $F L X)$ compared to water-treated controls, irrespective of strain. BALB/cJ mice treated with the lower, but not higher, fluoxetine dose showed more immobility than C57BL/6J regardless of treatment ( $n=8-10 /$ strain/treatment). $*_{p}<0.05 \mathrm{BALB} / \mathrm{cJ}$ vs. C57BL/6J. Data are means \pm SEM 
Table 1

Chronic fluoxetine treatment in adult BALB/cJ and C57BL/6J mice did not significantly alter exploratory and, anxietyrelated behaviors, fear conditioning or extinction, or behavioral responses to swim stress, when tested 3 weeks after treatment cessation

\begin{tabular}{|c|c|c|c|c|}
\hline \multirow[t]{2}{*}{ Strain and treatment } & \multicolumn{2}{|l|}{ BALB/cJ } & \multicolumn{2}{|c|}{ C57BL/6J } \\
\hline & Water & FLX & Water & FLX \\
\hline Fluoxetine $(\mathrm{mg} / \mathrm{kg} / \text { day })^{*}$ & - & $11.7 \pm 1.4$ & - & $8.4 \pm 0.2$ \\
\hline Water (mL/kg/day) ${ }^{*}$ & $87.8 \pm 10.6$ & - & $60.4 \pm 3.7$ & - \\
\hline \multicolumn{5}{|l|}{ Novel open field } \\
\hline Total distance $(\mathrm{m}){ }^{* *}$ & $11.0 \pm 3.9$ & $11.2 \pm 8.7$ & $83.3 \pm 6.0$ & $74.3 \pm 10.3$ \\
\hline Percent center time ${ }^{* *}$ & $2.6 \pm 1.2$ & $1.0 \pm 0.6$ & $17.7 \pm 2.6$ & $13.9 \pm 1.9$ \\
\hline \multicolumn{5}{|l|}{ Elevated plus-maze } \\
\hline Open arm time $(\mathrm{s}){ }^{* *}$ & $0.2 \pm 0.2$ & $3.3 \pm 2.1$ & $21.2 \pm 6.4$ & $29.4 \pm 3.6$ \\
\hline Open arm entries & $0.4 \pm 0.4$ & $1.0 \pm 0.7$ & $5.3 \pm 0.7$ & $6.1 \pm 0.7$ \\
\hline Closed arm entries & $31.6 \pm 5.0$ & $25.2 \pm 8.7$ & $23.2 \pm 1.7$ & $25.1 \pm 1.4$ \\
\hline \multicolumn{5}{|l|}{ Fear conditioning } \\
\hline Baseline freezing & $0.0 \pm 0.0$ & $0.0 \pm 0.0$ & $0.0 \pm 0.0$ & $0.0 \pm 0.0$ \\
\hline Trial 1 freezing & $0.0 \pm 0.0$ & $0.0 \pm 0.0$ & $2.0 \pm 2.0$ & $0.0 \pm 0.0$ \\
\hline Trial 2 freezing & $5.7 \pm 5.7$ & $3.3 \pm 3.3$ & $24.0 \pm 9.3$ & $18.0 \pm 10.1$ \\
\hline Trial 3 freezing & $20.0 \pm 6.2$ & $13.3 \pm 6.7$ & $46.0 \pm 6.7$ & $42.0 \pm 8.7$ \\
\hline \multicolumn{5}{|l|}{ Fear extinction } \\
\hline 1st trial-block freezing & $34.8 \pm 8.0$ & $28.9 \pm 11.6$ & $39.0 \pm 4.9$ & $51.7 \pm 7.1$ \\
\hline 10th trial-block freezing & $8.6 \pm 8.0$ & $7.2 \pm 6.0$ & $4.7 \pm 2.3$ & $13.7 \pm 4.3$ \\
\hline \multicolumn{5}{|l|}{ Swim stress } \\
\hline Percent immobility & $79.5 \pm 3.2$ & $80.0 \pm 2.1$ & $78.8 \pm 1.9$ & $82.5 \pm 2.5$ \\
\hline
\end{tabular}

$n=6-10 /$ strain/treatment

*

$p<0.05 \mathrm{BALB} / \mathrm{cJ}$ versus C57BL/6J

$* *$

$p<0.01 \mathrm{BALB} / \mathrm{cJ}$ versus C57BL/6J 
Table 2

Effects of chronic fluoxetine treatment in adolescent BALB/cJ and C57BL/6J mice on cortical and hippocampal 5-HT or 5-HTIAA tissue content measured approximately 8 weeks later

\begin{tabular}{|c|c|c|c|c|}
\hline \multirow[t]{2}{*}{ Strain and treatment } & \multicolumn{2}{|c|}{$\mathbf{B A L B} / \mathbf{c J}$} & \multicolumn{2}{|c|}{ C57BL/6J } \\
\hline & Water & FLX & water & FLX \\
\hline \multicolumn{5}{|l|}{ Lower dose } \\
\hline Cortical 5-HT & $475 \pm 29$ & $473 \pm 36$ & $423 \pm 58$ & $440 \pm 66$ \\
\hline Cortical 5-HIAA & $125 \pm 6$ & $139 \pm 11$ & $140 \pm 22$ & $144 \pm 22$ \\
\hline Hippocampal 5-HT & $192 \pm 18$ & $248 \pm 36$ & $310 \pm 30$ & $246 \pm 36$ \\
\hline Hippocampal 5-HIAA & $102 \pm 9$ & $121 \pm 18$ & $152 \pm 16$ & $149 \pm 26$ \\
\hline \multicolumn{5}{|l|}{ Higher dose } \\
\hline Cortical 5-HT & $428 \pm 42$ & $477 \pm 21$ & $459 \pm 97$ & $502 \pm 54$ \\
\hline Cortical 5-HIAA & $122 \pm 12$ & $130 \pm 5$ & $139 \pm 27$ & $146 \pm 16$ \\
\hline Hippocampal 5-HT ${ }^{* *}$ & $453 \pm 20$ & $411 \pm 24$ & $485 \pm 45$ & $623 \pm 57$ \\
\hline Hippocampal 5-HIAA ${ }^{* *}$ & $253 \pm 12$ & $212 \pm 9^{*}$ & $283 \pm 23$ & $360 \pm 29$ \\
\hline
\end{tabular}

$n=8-10 /$ strain/treatment. BALB/cJ mice receiving the higher fluoxetine dose had lower levels of hippocampal 5-HIAA, but not 5-HT, compared to vehicletreated $\mathrm{BALB} / \mathrm{cJ}$, while a trend $(p=0.052)$ for the opposite pattern was seen in $\mathrm{C} 57 \mathrm{BL} / 6 \mathrm{~J}$.

* $p<0.05$ versus water/same strain

$* *$

$p<0.01 \mathrm{BALB} / \mathrm{cJ}$ vs. C57BL/6J (collapsed across treatment). 